\title{
COSTA Rica: LA TERCERA NO FUE LA VENCIDA, FRACASO DE LA REFORMA FISCAL DE LUIS GUILLERMO SOLÍs*
}

\author{
Costa Rica: Third time's a charm? \\ Not for Luis Guillermo Solís's tax reforms
}

\section{FABIÁN A. BORGES}

California State University, San Bernardino, USA

\section{RESUMEN}

La política costarricense durante 2016 fue dominada por el debate y eventual fracaso de las reformas tributarias promovidas por la administración Solís. Este fracaso es emblemático de una crisis de gobernabilidad más generalizada, marcada por crecientes niveles de fragmentación y polarización partidaria que hacen cada vez más difícil forjar acuerdos sobre temas nacionales de transcendencia. Las elecciones programadas para febrero 2018 dominarán la política durante 2017.

Palabras clave: Costa Rica, relaciones Ejecutivo-Legislativo, elecciones, partidos políticos, atasco político, reforma fiscal

\begin{abstract}
Costa Rican politics in 2016 were dominated by the debate and eventual failure of a tax reform proposed by the Solis administration. This failure is emblematic of a wider political crisis marked by growing levels of partisan fragmentation and polarization that have made it increasingly difficult to forge cross-partisan agreements on major national policy issues. Elections scheduled for February 2018 are expected to dominate politics during 2017.
\end{abstract}

Key words: Costa Rica, executive-legislative relations, elections, political parties, political gridlock, tax reform 


\section{TEMAS SALIENTES DE LA REALIDAD NACIONAL Y SU IMPACTO POLÍTICO}

\section{Coyuntura política}

La política costarricense durante 2016 giró alrededor de dos impasses —uno entre el Ejecutivo y el Legislativo y otro entre los diferentes partidos políticos representados en la Asamblea Legislativa - en cuanto a un paquete de reformas tributarias propuestas por la administración del presidente Luis Guillermo Solís como solución al preocupante deterioro reciente de las finanzas públicas. En enero 2017, luego de año y medio de negociar, amenazar y rogar, Solís abandonó sus reformas. A menos de doce meses de las próximas elecciones, los diputados dudarán en aumentar la carga tributaria del electorado. De tal manera, es altamente probable que Solís le herede a su sucesor la crisis de finanzas públicas que Laura Chinchilla (2010-2014) le heredó y que Oscar Arias (2006-2010) le heredó a Chinchilla.

Encuestas de opinión pública llevadas a cabo durante 2016 por el Centro de Investigación y Estudios Políticos (CIEP 2017) de la Universidad de Costa Rica muestran una estabilización a niveles bastante bajos en las percepciones sobre la gestión del gobierno y el rumbo del país. Solís ganó la elección de 2014 en segunda vuelta con el Partido Acción Ciudadana (PAC, centro-izquierda). Esa elección marcó la primera vez desde la fundación de la segunda república en 1949 que el Ejecutivo quedó en manos de un partido diferente a los dos tradicionales, Liberación Nacional (PLN, centro) y Unidad Social Cristiana (PUSC, centroderecha).

La combinación de un triunfo decisivo y la novedad de tener un gobierno de un partido no-tradicional crearon altas (algunos dirían imposibles) expectativas. La nueva administración casi inmediatamente chocó con la difícil realidad política costarricense. Como consecuencia, las percepciones ciudadanas sobre la gestión del gobierno declinaron precipitosamente (Alfaro-Redondo y Gómez-Campos 2016). En julio de 2014, a cien días de mandato, un 39\% consideraba a la gestión del gobierno Solís como "buena" o "muy buena". Al acabar la llamada "luna de miel", opiniones sobre la gestión empeoraron hasta estabilizarse con alrededor de $60 \%$ describiéndola como "mala" o "muy mala". Si bien negativos, estos resultados superan por cinco puntos en promedio a la calificación obtenida por Chinchilla (PLN) a finales de su administración. Aun así, la evaluación de la figura del Presidente ha empeorado continuamente conforme ha avanzado la administración. En julio de 2014, Solís recibió una calificación promedio de 7,3 en una escala de 0-10. Esta calificación se redujo a 4,5 en la última encuesta de 2016, por debajo de 5,2 que obtuvo Chinchilla 100 días después del fin de su mandato.

Si bien negativa, la opinión pública en cuanto al rumbo del país se mantuvo estable entre agosto 2015 y finales del 2016. Las personas que consideraban que el país viajaba por mal camino (53\%) superaban a las que pensaban lo opuesto 
(21\%) por un margen mayor a dos a uno. A partir de agosto 2016 se notó un leve repunte en el porcentaje de personas que calificaban al rumbo positivamente y un declive entre los que pensaban lo opuesto (ver gráfico 1).

Gráfico 1. Percepciones sobre el rumbo del país

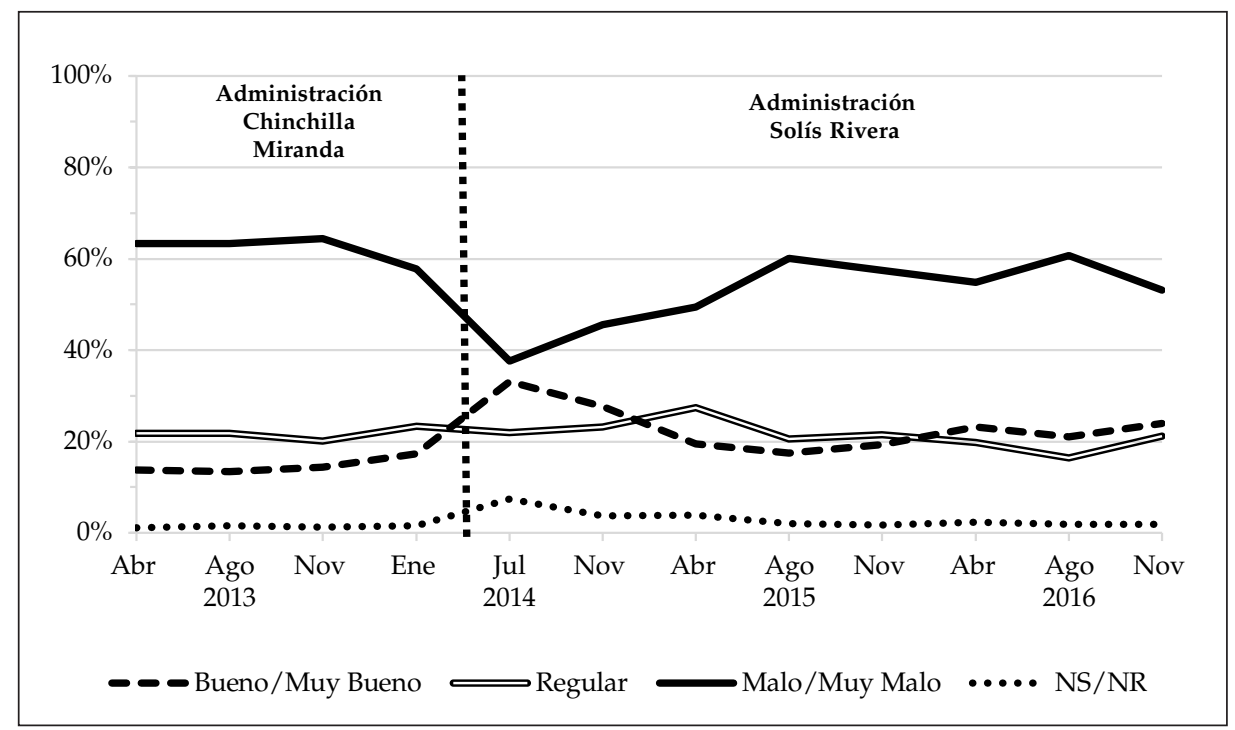

Fuente: CIEP (2017)

Este malestar popular responde en gran parte a la dificultad que ha tenido la administración de Solís para transformar en leyes las demandas de la sociedad. La Asamblea actual es la más fragmentada y polarizada en la historia reciente. A pesar del triunfo de Solís en las elecciones presidenciales, PAC constituye la segunda fracción legislativa más grande con solo 13 de los 57 (23\%) escaños. Esto obliga a sus diputados negociar y buscar alianzas con otros partidos.

El éxito legislativo depende de mantener control del Directorio Legislativo de la Asamblea, ya que este determina el orden en que los proyectos se debaten, decide a cuáles comisiones permanentes enviar los proyectos de ley y nombra los miembros de dichas comisiones (Alfaro-Redondo y Gómez-Campos 2016). PAC presidió sobre el Directorio durante 2014-2015 a través de una coalición ideológicamente incoherente con el Frente Amplio (FA, izquierda) y PUSC. Dicha coalición terminó un año después, cuando PUSC condicionó su participación en la alianza a que la administración de Solís y el PAC abandonaran sus planes de introducir una reforma fiscal (La Nación 2015, 30 de abril).

Esto hizo posible que la Alianza Opositora, una coalición de siete partidos, asumiera control del directorio durante 2015-2016 y 2016-2017. La Alianza, que controlaba 34 escaños (60\%), incluye al PLN, PUSC, Movimiento Libertario 
(derecha) y cinco diputados de cuatro partidos evangélicos. ${ }^{1}$ La pérdida de control sobre el Directorio jugó un papel clave en el fracaso de la reforma fiscal (ver sección V). La Alianza nombró y luego reeligió como presidenta de la Comisión de Asuntos Hacendarios a la diputada Rosibel Ramos (PUSC), quien consistentemente obstruyó a las reformas.

Es poco probable que la baja productividad legislativa se reverse durante el 20162017. Ya desde finales del 2016 la atención de los diputados empezó a centrarse en las elecciones de febrero de 2018. Al menos 7 diputados (12\%), y posiblemente hasta $10(18 \%)$, lanzarán campañas presidenciales. Dada la prohibición sobre la reelección inmediata de diputados, aquellos que no planean competir por la presidencia estarán ocupados buscando sus próximos trabajos, ya sea en el Ejecutivo (si su partido gana la presidencia) (Carey 1996) o fuera del gobierno.

\section{COYUNTURA SOCIOECONÓMICA}

Si bien sólido, el crecimiento de la economía costarricense durante el 2016 no fue lo suficientemente rápido como para reducir de manera sustancial el desempleo, la pobreza y la desigualdad. Las finanzas públicas continúan siendo la mayor debilidad de la economía. La deuda pública aumentó por octavo año consecutivo y se acerca al 50\% del producto interno bruto (PIB), un nivel considerado insostenible para una economía emergente (FMI 2016: 57).

La economía continuó acelerando en 2016 pero aún no regresa a los niveles de crecimiento experimentados previo a la crisis financiera global. Impulsada principalmente por la demanda interna, la economía creció 4,3\% en 2016, comparada con $3,7 \%$ en 2015 . Se esperan tasas de crecimiento similares $(4,1 \%)$ durante los próximos dos años (BCCR 2017). De tal modo, el crecimiento se mantiene por debajo del promedio de $4,9 \%$ reportado durante la década previa a la crisis.

Las finanzas públicas continúan siendo el talón de Aquiles de la economía. El déficit fiscal del gobierno central fue equivalente a 5,2\% del PIB en 2016, una mejoría leve relativa al déficit de 5,7\% de 2015 (ver gráfico 2). En enero de 2017, el gobierno retiró la reforma fiscal que, desde mediados de 2015, había sido su principal prioridad legislativa. Dicha reforma hubiese generado aproximadamente $2,5 \%$ de PIB en nuevos recursos. Si bien los esfuerzos por parte de la administración de Solís por reducir la evasión fiscal incrementaron los ingresos del gobierno central un 9,1\%, la mayoría de estos se utilizaron para cubrir un incremento en gastos corrientes (excluyendo intereses) de 5,8\%. Como consecuencia del alto déficit fiscal, la deuda del gobierno central llegó a 45,3\% del PIB en 2016. Ausente una reforma fiscal, podría llegar a 49,3\% del PIB a

Estos son: Alianza Demócrata Cristiana, Renovación Costarricense y Restauración Nacional. Si bien no es explícitamente cristiano, Accesibilidad sin Exclusión vota con ellos. 
finales de 2017 y 61,2\% del PIB en 2020 (La Nación 2017, 20 de febrero). Citando la falta de reforma fiscal, la agencias calificadores Moody's y Fitch rebajaron la nota de riesgo de la deuda costarricense a principios de 2017.

\section{Gráfico 2. Finanzas públicas}

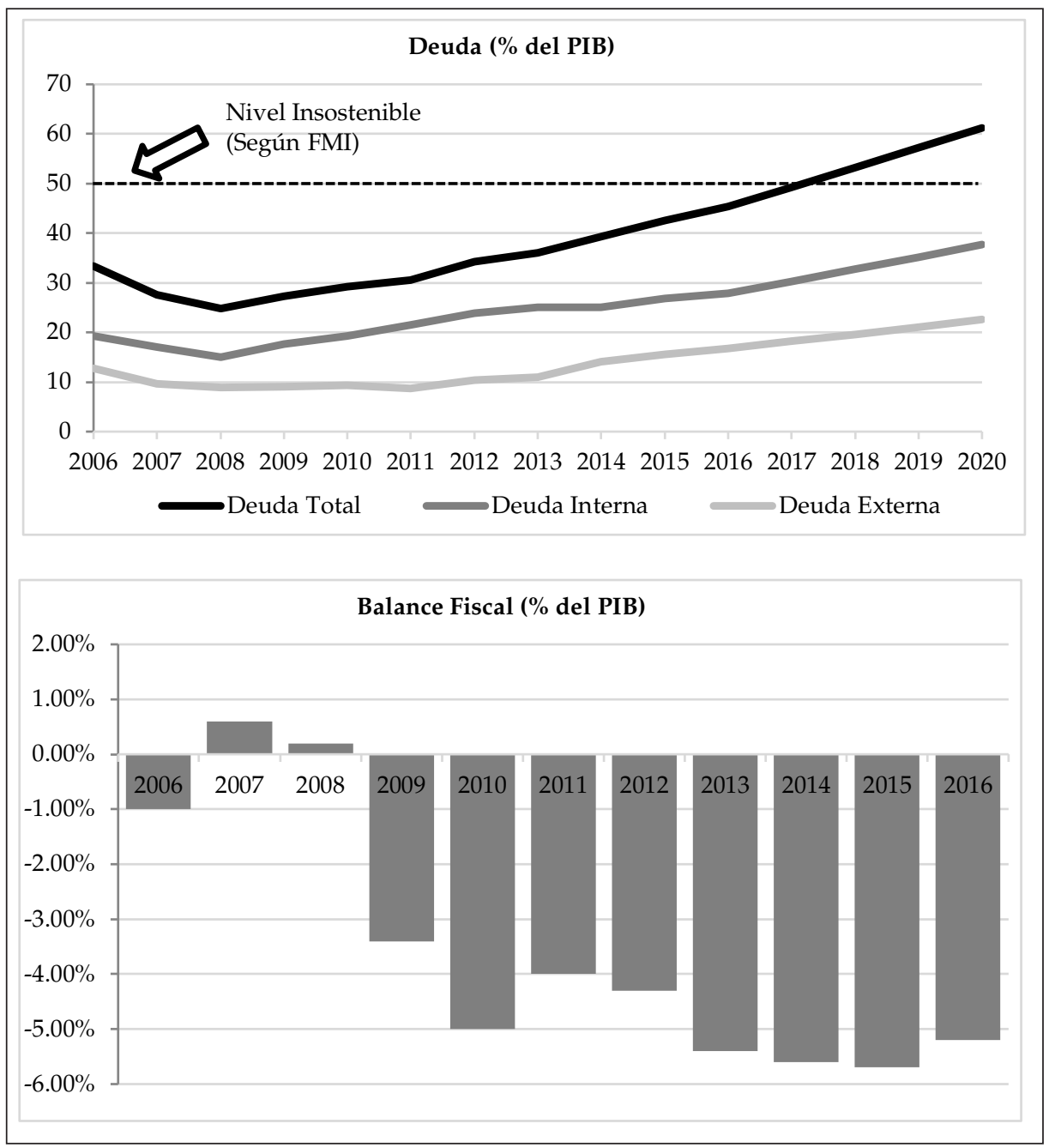

Fuente: Ministerio de Hacienda (2017)

La actual trayectoria de altos déficits y creciente deuda inició a finales de la administración Arias con la implementación del Plan Escudo, un paquete de estímulo fiscal contracíclico para mitigar el impacto de la crisis financiera global. Dicho paquete incluyó aumentos en los montos y cobertura de programas sociales dirigidos a los pobres y otorgó alimentos gratis a familias pobres con hijos (Feoli 2009; Villareal y Gómez 2010). Además, dicha administración aprobó 
un alza significativa en los salarios públicos e incrementó la planilla pública en un 20\% (PEN 2011).

El fracaso de una reforma fiscal ha sido un episodio recurrente en la política costarricense reciente. Incluyendo a Solís, tres de los últimos cuatro presidentes, representantes de tres partidos distintos, han dedicado años de sus mandatos y gastado gran parte de su capital político promoviendo reformas fiscales fallidas. El fracaso de dichos planes constituye un ejemplo emblemático de la crisis de gobernabilidad que el país ha vivido luego de la transición de un sistema político bipartidista estable a uno multipartidista con altos (y crecientes) niveles de polarización (ver sección $\mathrm{V}$ ).

La pobreza se redujo levemente durante el 2016. Según el Instituto Nacional de Estadística y Censos (INEC 2016), 20,5\% de los hogares (307.270) vivían en pobreza. Esto representa una reducción estadísticamente significativa en comparación con el año anterior $(21,7 \%)$ y una continuación de la tendencia iniciada en 2014 (22,3\%). La pobreza extrema, por su parte, afectó a 6,3\% de los hogares (95.004). En números absolutos, 1.115.261 personas vivían en pobreza (22,9\% de la población). Esto representa una disminución de 22.620 personas ( 0,7 puntos porcentuales) en comparación con el año anterior $(23,6 \%)$. La pobreza extrema afectó a 343.357 personas $(7,0 \%)$, una disminución de 0,8 puntos porcentuales o alrededor de 38.800 personas. No obstante, cabe recalcar que el nivel de pobreza se ha mantenido estancado cerca del $20 \%$ desde mediados de los noventa. Esta situación es particularmente problemática en tanto la población del país continúa creciendo y, por tanto, una tasa de pobreza constante significa un aumento en el número absoluto de hogares pobres.

Si bien menos costarricenses viven en pobreza, la distribución del ingreso empeoró. El coeficiente de Gini aumentó levemente a 0,521, comparado con 0,516 en 2015 y 2014. Tradicionalmente uno de los países más igualitarios de América Latina, Costa Rica hoy en día posee un nivel de desigualdad superior al promedio regional de 0,491 (CEPAL 2016). Si bien esta tendencia es preocupante, cabe mencionar que existen diferencias importantes en cómo diversos países calculan este índice (El Financiero 2014, 30 de abril).

El desempleo es la principal causa del alto nivel de desigualdad. Según INEC (2017), la tasa de desempleo fue de 9,5\% en 2016. El desempleo afecta de manera desproporcionada a los pobres, las mujeres, los jóvenes y, en especial, las personas con bajos niveles de escolaridad (El Financiero 2015, 8 de noviembre). La alta tasa de desempleo entre el $20 \%$ más pobre de la población es una de las principales razones por las cuales Costa Rica ha tenido éxito limitado reduciendo la pobreza y desigualdad en años recientes. 


\section{Coyuntura subregional e internacional}

En un análisis de la política exterior costarricense durante 2014-2016, Cascante et al. (2016: 46) notan que: "en la cultura popular existe un adagio respecto de las tres estaciones climáticas de Costa Rica: el invierno, el verano y el conflicto con Nicaragua". Los principales temas de política exterior costarricense durante 2016 giraron alrededor de esta difícil relación bilateral.

La desarticulación por parte del gobierno costarricense de una red internacional de tráfico de personas el 10 noviembre de 2015 desató una crisis migratoria cuyas consecuencias aún se sienten. Dicha red facilitaba el tránsito entre Costa Rica y Nicaragua de inmigrantes que viajaban hacia los Estados Unidos. La crisis estalló el 14 de noviembre cuando el gobierno nicaragüense cerró la frontera con Costa Rica y ordenó a sus fuerzas armadas prevenir el ingreso de los migrantes. Esto dejó a casi 8.000 cubanos varados en Costa Rica (La Nación 2016, 15 de marzo).

La tensa relación bilateral empeoró el mes siguiente al fallar la Corte Internacional de Justicia en La Haya a favor de Costa Rica en su disputa fronteriza con Nicaragua. Dicha querella fue planteada por el país en respuesta a la ocupación en noviembre 2010 por tropas nicaragüenses de la Isla Portillos, una sección de tres kilómetros cuadrados de la Isla Calero, que está situada en el río San Juan en el extremo este de la frontera (Alfaro-Redondo y Gómez-Campos 2014). Las tensiones incrementaron más aun en abril de 2016 luego del anuncio por parte del presidente nicaragüense Daniel Ortega de la compra de 50 tanques rusos y otros tipos de armamentos por \$ 80 millones (La Nación 2016, 26 de abril).

La crisis migratoria fue consecuencia de la normalización de las relaciones diplomáticas entre Cuba y los Estados Unidos. Los cubanos predijeron acertadamente que este acercamiento culminaría con la eliminación de la política migratoria preferencial que Estados Unidos les ha otorgado a cubanos desde la Guerra Fría. ${ }^{2}$ De tal manera, el número de cubanos admitidos a los Estados Unidos incrementó de aproximadamente 10.000 al año durante 20052013 a 24.278 en 2014, 43.159 en 2015 y, finalmente, 56.406 en 2016 (Krogstad 2017, 13 de enero). Temiendo el fin su estatus preferencial, desde finales del 2014 decenas de miles de cubanos empezaron a viajar por aire a Ecuador —el único país continental que no les exigía visa de ingreso (El Comercio 2015, 6 de noviembre). De ahí iniciaban un largo viaje por tierra hacía la frontera sur de Estados Unidos vía el istmo centroamericano.

La desarticulación de la banda de traficantes y el cierre de la frontera hicieron visible la magnitud del tráfico de cubanos y otros migrantes por Centroamérica (La Nación 2015, 10 de noviembre). El gobierno costarricense respondió a la crisis otorgándoles visas temporales a los cubanos e invirtiendo cerca de \$ 2 millones en la construcción

2 En enero 2017, el presidente estadounidense Barak Obama suspendió el trato migratorio preferencial para los cubanos. 
de 44 albergues y la provisión de asistencia humanitaria (La Nación 2016, 15 de marzo). Solís solicitó una solución regional a la crisis pero topó con fuerte resistencia por parte de Nicaragua, Guatemala y Belice. Como protesta, en diciembre 2015 Solís rompió relaciones con el Sistema de la Integración Centroamericana. Costa Rica finalmente regresó a la organización en junio de 2016.

El 28 de diciembre de 2015 se logró coordinar una solución. Dada la negativa de Nicaragua a abrir sus fronteras, los demás cancilleres centroamericanos acordaron abrir un "paso excepcional" para los migrantes por su territorio luego de que estos volaran de Costa Rica a El Salvador o México. Entre el 12 de enero y el 15 de marzo, 4.818 cubanos participaron en estos vuelos. Otros 3.004 salieron del país por cuenta propia (La Nación 2016, 15 de marzo).

Sin embargo, esto no significó el fin de los flujos migratorios. A partir de abril empezaron a llegar inmigrantes haitianos a un ritmo de 150 por día. A finales del año se estimaba que unos 10.900 haitianos habían ingresado al país (La Nación 2016, 28 de septiembre). Dichos migrantes provenían en su mayoría de Brasil, que les abrió las puertas en 2010 luego de que la isla sufriese un terremoto de magnitud 7,0. Se estima que unos 130.000 haitianos inmigraron a Brasil, donde trabajaron en la construcción de instalaciones para la Copa Mundial de Fútbol de 2014 y las Olimpiadas de Río de Janeiro de 2016 (Agência Brasil 2016, 12 de junio). Al completarse las obras y dada la severa crisis económica que enfrenta ese país, decenas de miles de haitianos iniciaron su propia travesía terrestre hacía los Estados Unidos vía el istmo centroamericano. Al igual que los cubanos, los haitianos se quedaron varados en Costa Rica al chocar con la frontera nicaragüense.

En cuanto al fallo de la corte internacional, el consenso indica que fue "ampliamente favorable para los intereses costarricenses" (Cascante et al. 2016: 42). El fallo declaró ilegal la intervención nicaragüense, confirmó la soberanía costarricense sobre el territorio en cuestión y condenó a Nicaragua a pagar daños por la ocupación. En junio, la Cancillería costarricense solicitó \$ 6,7 millones. Managua rechazó esa cifra. La ICJ determinará el monto final.

Mirando hacia 2017, el gobierno de Donald Trump será la principal fuente de incertidumbre internacional para Costa Rica. Estados Unidos es un mercado fundamental para las exportaciones costarricenses. Durantela contienda electoral de 2016, Trump fue claro en su deseo de replantear las relaciones comerciales internacionales de su país. Curiosamente, los principales asesores económicos de Trump, ambos proteccionistas, han expresado apoyo por el Tratado de Libre Comercio entre Estados Unidos, Centroamérica y República Dominicana (CAFTA-DR), del cual Costa Rica forma parte. Si bien sus argumentos son considerados erróneos por la mayoría de economistas, Wilbur Ross, el actual Secretario de Comercio, y Peter Navarro, el director del Consejo Nacional de Comercio, han descrito al CAFTA-DR como uno de los TLCs más exitosos que ha firmado Estados Unidos ya que dicho país mantiene un superávit comercial con la región (Ross y Navarro 2016, 15 de agosto). 


\section{ELECCIONES PRESIDENCIALES Y LEGISLATIVAS 2018}

Los preparativos para las elecciones presidenciales y legislativas del 8 de febrero de 2018 dominarán la política costarricense durante 2017. Para ser electo presidente, un candidato deberá obtener la pluralidad del voto. Si el candidato con el mayor número de votos obtiene menos del $40 \%$ de los votos válidos, los dos candidatos con el mayor número de electores participarán en una segunda ronda en abril. Los 57 diputados se eligen proporcionalmente y cada una de las siete provincias constituye un distrito electoral.

\section{Demanda electoral}

Vale la pena empezar el análisis de las elecciones revisando algunas de las principales preocupaciones de los costarricenses a finales de 2016, según CIEP (2017). Tres veces más costarricenses describen el rumbo del país como negativo que positivo (ver gráfico 1 ). Si bien la figura del candidato es decisiva en las elecciones presidenciales, este "malestar" hará difícil que PAC logre una segunda administración consecutiva.

Gráfico 3. Problemas principales

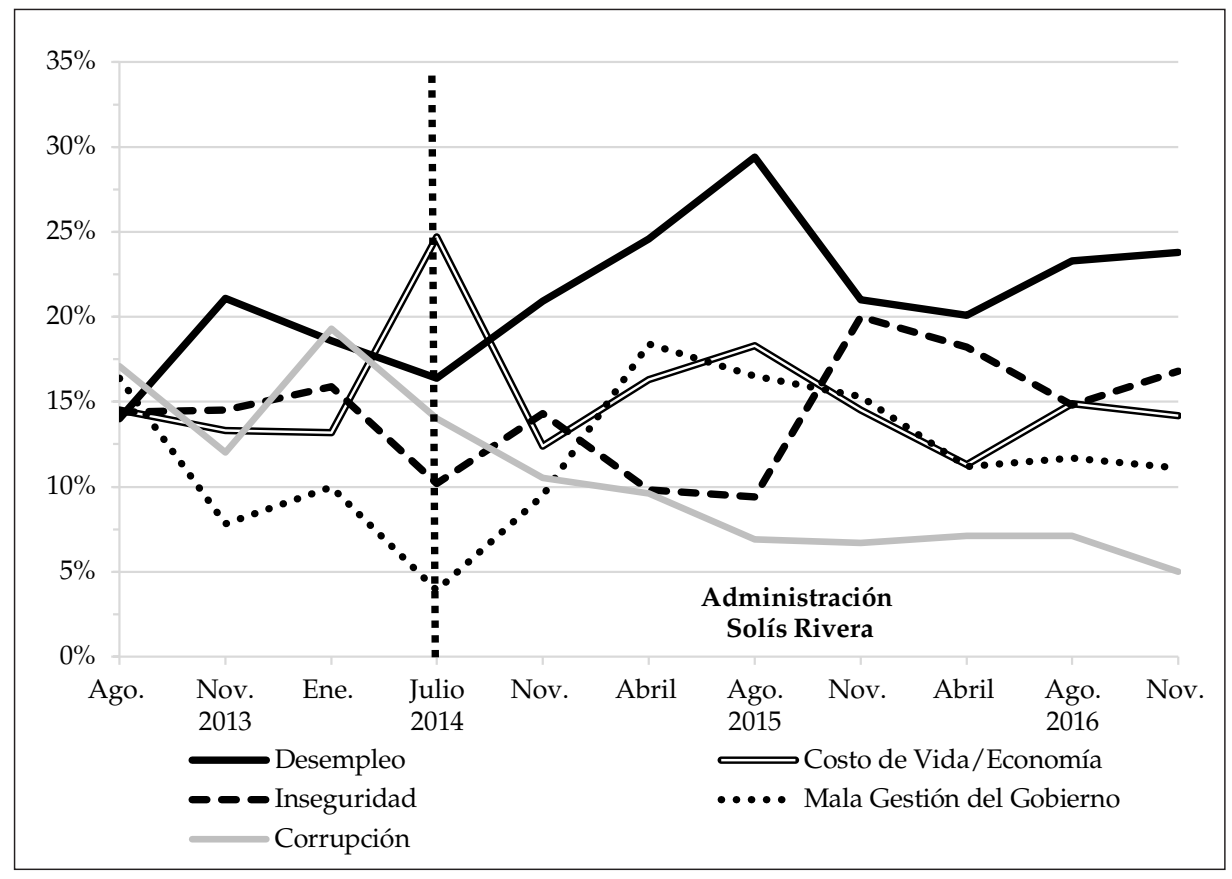

Fuente: CIEP (2017) 
El gráfico 3 muestra las principales preocupaciones de los costarricenses. El desempleo fue, por un amplio margen, la más importante (24\%). Un $14 \%$ adicional citó el costo de la vida. Después de haber perdido importancia como consecuencia de las exitosas políticas de la administración Chinchilla, inseguridad y delincuencia han crecido como preocupación desde mediados de 2015 (ver sección III). En cambio, la opinión de los costarricenses sobre la habilidad de la administración de gobernar efectivamente ha mejorado. A finales de 2016, 11\% expresaba preocupación sobre la gestión de la administración, bastante menos que el 18\% que citaba esta preocupación en abril de 2015 . Además, cabe mencionar una precipitosa caída en el porcentaje de la población que cita a la corrupción como el principal problema (ver sección III).

\section{Oferta electoral}

Es riesgoso tratar de predecir los resultados de las elecciones con un año de anticipación. Los costarricenses muestran poco apego a los partidos políticos, sus votos a menudo refutan las encuestas y muchos escogen candidatos a finales del proceso electoral. Tan solo $27 \%$ de los costarricenses se identifica con un partido (CIEP 2017: 39), comparado con alrededor del 95\% a mediados de los noventa (Vargas Cullel et al. 2006: 22-23). Durante la elección de 2014, 36,4\% de los votantes decidió por quién iba a votar la semana de las elecciones y solo $18,5 \%$ estaba decidido a cinco meses de las elecciones (Rosales 2015: 165).

Como partido de un presidente impopular incapaz de cumplir con las imposiblemente altas expectativas de haber sido el primero electo por un partido no tradicional, PAC enfrenta serias desventajas. Aun así, PAC no debería ser subestimado. Ha sido la segunda fuerza política del país desde el colapso del PUSC en 2004. Si bien solo 3,1\% de los encuestados en noviembre de 2016 simpatizaba con PAC (CIEP 2017: 39), las encuestas consistentemente subestiman el apoyo de este partido. Esto probablemente se debe a que su base es principalmente urbana y de clase media alta (Alfaro-Redondo and GómezCampos 2015: 14-15), grupos más propensos a describirse como independientes que tienden a votar por el candidato en lugar del partido.

El PAC será representado por Carlos Alvarado, el ex-Ministro de Trabajo de Solís, quien se ha presentado explícitamente como el candidato de la continuidad (La Nación 2017, 21 de enero). Alvarado ganó la nominación en julio de 2017, derrotando a Welmer Ramos, el ex-Ministro de Economía de Solís, por un margen de $57 \%$ a $43 \%$. Después de mucha especulación, la actual diputada Epsy Campbell, una de las fundadoras del partido y una de las políticas costarricenses más populares (El Mundo CR 2017, 15 de febrero), decidió no buscar la nominación.

Luego de una decepcionante experiencia con el "cambio" es muy posible que los votantes opten por volver a las "manos seguras" del PLN, el partido que históricamente ha dominado la política costarricense. La combinación de los 
bajos niveles de apoyo de la actual administración, la base partidaria más grande y leal del país, control de la mayoría de las alcaldías y un candidato fuerte hacen del PLN el favorito para las próximas elecciones. Según CIEP (2017, 39), 15,4\% de los votantes simpatiza con el partido. PLN ha estado fuera del poder por dos periodos consecutivos únicamente una vez en su historia (1998-2006).

PLN será representado por el expresidente de la Asamblea Antonio Álvarez Desanti, quien derrotó al expresidente José María Figures (1994-1998) en la convención partidaria de abril de 2017 por un margen de $45 \%$ a 37\%. La pugna por la candidatura del PLN fue tensa. La lentitud del tribunal interno del PLN al contar los votos de la convención llevó a Álvarez Desanti a expresar sospechas sobre el proceso e inclusive mencionar la posibilidad de fraude, aunque "retiró" dicha palabra el día siguiente (La Nación 2017, 3 de abril).

El apoyo de figuras importantes dentro del partido y la extremadamente baja popularidad de Figures entre votantes no afiliados con el PLN (El Mundo CR 2017, 15 de febrero) posibilitaron el eventual triunfo de Alvárez Desanti. Durante 2016 se especulaba sobre si el expresidente Oscar Arias (1986-1990 y 2006-2010), el segundo político más popular (El Mundo CR 2017, 15 de febrero), lanzaría una tercera campaña presidencial. La especulación acabó en septiembre y en enero la poderosa ala "arista" del PLN dio su adhesión a Álvarez Desanti. En febrero de 2017 el equipo político del alcalde de San José, la capital, y candidato presidencial del PLN en 2014, Johnny Araya empezó a trabajar a favor de Álvarez Desanti.

Dado por muerto luego de los escándalos de corrupción de 2004, PUSC fue el segundo partido en cuanto a número de alcaldías ganadas en las elecciones municipales de 2014 (Alfaro-Redondo y Gómez-Campos 2016: 109) y se mantiene como segundo partido con más simpatizantes (6,8\%) (CIEP 2017: 39). PUSC será representado por Rodolfo Piza, quien en junio de 2017 fácilmente derrotó a Rafael Ortiz, actual diputado y expresidente del equipo de fútbol Liga Deportiva Alajuelense, por un margen de 69\% a 24\%. Esta será la segunda candidatura a la presidencia de Piza, quien en 2014 obtuvo 6\% del voto. 
Gráfico 4. Conocimiento y opiniones sobre candidatos a la presidencia (febrero 2017)

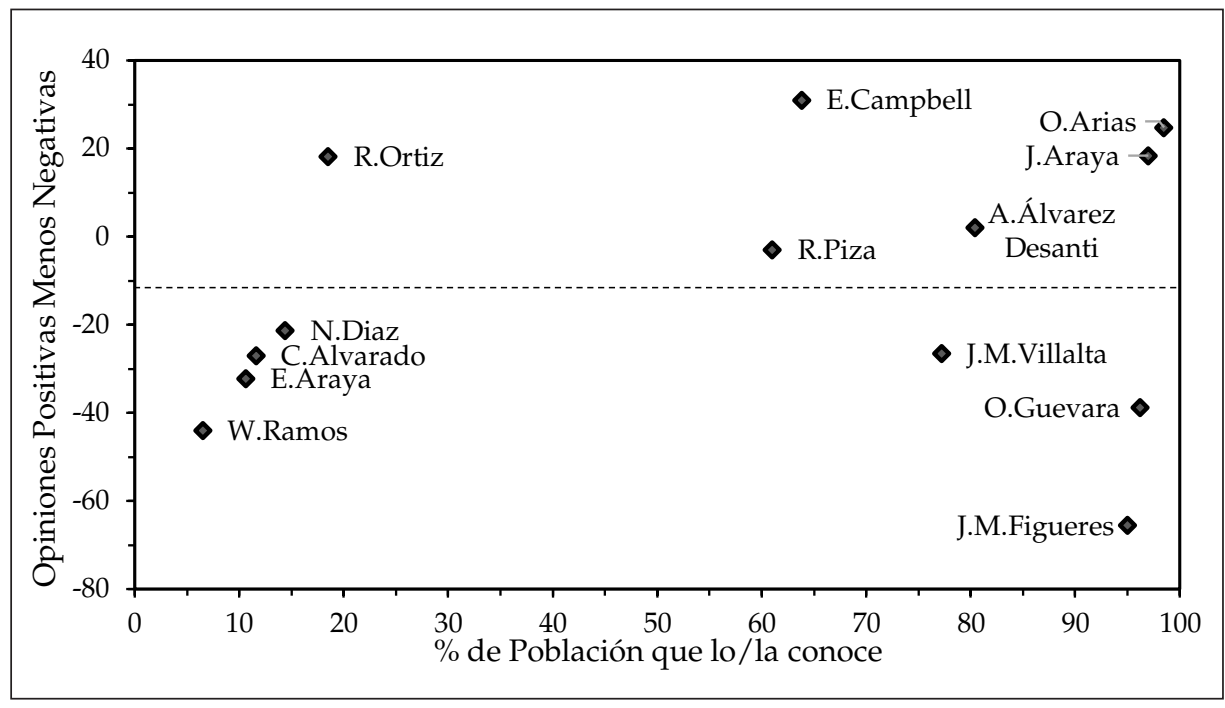

Fuente: El Mundo CR (2017, 15 de febrero)

A pesar de perder casi la mitad de sus diputaciones en 2014 en comparación con 2010 y no obtener ninguna alcaldía en 2016, Movimiento Libertario será representado por quinta vez por el actual diputado Otto Guevara. El ganó la nominación en junio de 2017, fácilmente derrotando a la diputada Natalia Díaz por un margen de 59\% a 41\%. Guevara ha dicho que emulará la campaña de Donald Trump, combinando la tradicional política libertaria de reducir impuestos y el tamaño del Estado con un nuevo énfasis en excluir a inmigrantes nicaragüenses de las políticas sociales e, inclusive, negarles ciudanía a sus hijos (La Nación 2016, 16 de noviembre).

El futuro del Frente Amplio es incierto. Dicho partido fue la gran sorpresa de 2014, cuando obtuvo 17\% del voto para Presidente y nueve diputaciones (Alfaro-Redondo y Gómez-Campos 2014). José María Villalta, el carismático candidato del partido en ese momento, no buscará la presidencia en 2018. FA será representado por el diputado Edgardo Araya, quien es poco conocido a pesar de su rol en la lucha en contra de una controversial concesión minera.

La gran sorpresa de 2018 podría ser Juan Diego Castro, un abogado penalista y exministro de seguridad durante la administración Figueres, quien representará al Partido Integración Nacional. Castro se ha reinventado como un outsider utilizando redes sociales para denunciar a políticos y burócratas por supuestos actos de corrupción y despilfarro y al sistema penal por supuesta debilidad ante el crimen. Su campaña se centrará en la promesa de "una democracia directa, sin partidos políticos y sin corruptos" y mano dura frente al crimen. Encuestas 
publicadas durante el primer trimestre de 2017 mostraban a Castro en segundo lugar detrás de Álvarez Desanti (Diario Extra 2017, 4 de mayo).

\section{PODER EJECUTIVO}

La atención de la administración Solís estuvo enfocada en la propuesta reforma fiscal debatida en la Asamblea. Este tema será discutido en detalle en la sección V. Las próximas dos secciones se enfocaran en los demás temas que ocuparon la agenda política durante 2016.

Enfrentando el Congreso más fragmentado en la historia del país y con control de tan solo 13 (23\%) de los 57 escaños legislativos, el Ejecutivo tuvo serias dificultades para lograr la aprobación de su agenda legislativa. Según datos compilados por el Estado de la Nación, las legislaturas 2014-2015 y 20152016 han sido poco productivas en cuanto a aprobación de proyectos de ley propuestos por el Ejecutivo (ver gráfico 5). ${ }^{3}$ Durante este tiempo la Asamblea aprobó 40 leyes del Ejecutivo, 26 de estas durante la segunda legislatura. Este número representa poco más de la mitad del promedio de 69,7 leyes aprobadas durante los primeros dos años de las seis administraciones anteriores. Sin embargo, este número es superior al de la administración Arias (35) y no mucho menor que el de la administración Pacheco (45).

Más allá del ámbito legislativo, la administración logró estabilizar su gabinete, presidió sobre un deterioro importante en seguridad pública y tuvo logros significativos en el manejo de desastres naturales, la ausencia de escándalos de corrupción mayores y la reducción en el número de protestas públicas.

La composición del gabinete se ha estabilizado luego de un 2015 tempestuoso en el que el gobierno perdió 17 (23\%) de sus 75 ministros, viceministros y presidentes ejecutivos originales (Alfaro-Redondo y Gómez-Campos 2016). En cambio, durante 2016, ocurrieron únicamente seis (8\%) renuncias y solo dos de estas fueron ministros. Dos ministros adicionales renunciaron a principios de 2017 al oficializar sus precandidaturas presidenciales. 
Gráfico 5. Número de leyes aprobadas por origen (primeras dos Legislaturas)

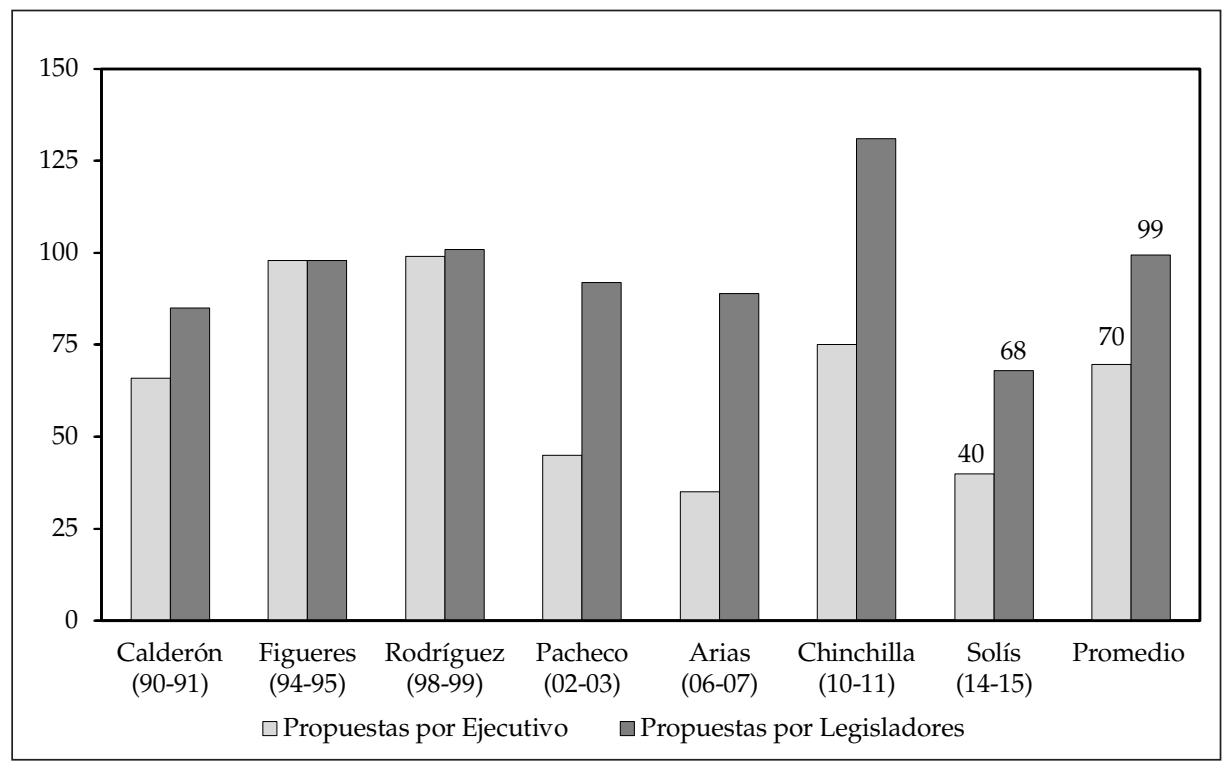

Fuente: Estado de la Nación

En cuanto a la seguridad pública, esta se ha deteriorado. Tanto el número absoluto de homicidios como la tasa de homicidios (por 100.000 habitantes) se incrementaron a sus niveles históricos más altos. Durante 2014-2016, el número anual de homicidios aumentó de 471 a 577 mientras que la tasa de homicidios fue de 9,9 a 11,8, sobrepasando el nivel considerado "epidemia" por la Organización Mundial de la Salud $(10,0)$. Estos resultados contrarrestan los logros de la administración Chinchilla en el área. La preocupación sobre la inseguridad ha crecido continuamente durante el actual gobierno luego de declinar durante el gobierno pasado. Durante la segunda mitad de 2016, el 17-20\% de la población consideró la inseguridad el principal problema del país (ver gráfico 3). Expertos en el tema (Loría 2015) y representantes del Poder Judicial concuerdan (La Nación 2017, 3 de enero) que el alza responde principalmente a "ajuste de cuentas" entre grupos de crimen organizado involucrados en el narcotráfico. Anteriormente, los delincuentes vinculados con esta actividad operaban como vendedores independientes sin mayores vínculos entre sí. Organizaciones más sofisticadas que luchan por monopolizar partes de la capital han surgido en años recientes.

La administración ha tenido éxitos en otras áreas. A finales de 2016, Costa Rica tuvo su primera experiencia directa con un huracán. El 24 de noviembre Otto, un huracán categoría 2 con vientos de 155 kilómetros por hora, atravesó el norte del país de costa a costa, causando 10 muertes y dañando 1.600 viviendas en 412 de los pueblos más pobres del país (La Nación 2016, 2 de diciembre). La Comisión Nacional de Emergencias estima \$ 243 millones en daños (La Nación 
2017, 1 de marzo). Si bien el impacto fue serio, el manejo de la crisis fue bien visto por la población. Según una encuesta llevada a cabo en diciembre, 80,8\% de los costarricenses consideraron la labor de la administración "muy buena" o "buena” (El Mundo CR 2016, 9 de diciembre).

Solís también tuvo logros en el combate de corrupción y la paz social. La administración concluyó sus primeros dos años y medio sin mayores escándalos de corrupción. El combate a la corrupción ha sido el tema central en las campañas del PAC desde su fundación. Según CIEP (2017), la corrupción pasó de ser la principal preocupación de los costarricenses (19\%) en enero 2014 a ser la quinta preocupación (5\%) a finales del 2016 (ver gráfico 3). ${ }^{4}$ Contrarrestando una tendencia iniciada en 2011 (Gómez-Campos y Villareal 2013), la administración ha presidido sobre una reducción significativa en el número de protestas y manifestaciones. Guillén Araya (2016: 28) atribuye esta tendencia al perfil ideológico de la administración y las "trayectorias cruzadas" entre miembros de la administración y dichos movimientos.

\section{PODER LEGISLATIVO}

En mayo 2015, el control del Directorio de la Asamblea pasó de una coalición que incluía al partido de gobierno a una compuesta por seis partidos de oposición. Esto coincidió con leves incrementos en tanto la cantidad de leyes aprobadas (de 33 a 35) y en el tiempo de aprobación promedio de leyes (de 807 a 850 días), según los datos del Estado de la Nación. El número de leyes aprobadas durante las legislaturas 2014-2015 y 2015-2016 (68) fue casi un tercio menor que el promedio durante las primeras dos legislaturas de 1990-2014 (99). Así mismo, el tiempo promedio para apoyar una ley (828 días) superó al promedio de los primeros dos años de las seis asambleas anteriores (653 días) por más de un cuarto (ver gráfico 6). En cuanto a contenido, la gran mayoría de las leyes aprobadas no corresponden a las prioridades expresadas en la opinión pública o por expertos (Alfaro-Redondo y Gómez-Campos 2016: 116).

\footnotetext{
Las percepciones de corrupción eran particularmente altas a finales de administración Chinchilla debido a dos escándalos particularmente notables - la construcción de una trocha en la frontera con Nicaragua y el uso de un jet privado por Chinchilla para ir a una boda en Perú. Solís enfatizó estos escándalos durante su campaña. A los 100 días de su presidencia Solís anunció que había encontrado evidencia de 14 instancias de corrupción durante el gobierno anterior. Sin embargo, ninguna de estas denuncias llegó a acusación penal (La Nación 2016, 22 de octubre).
} 
Gráfico 6.Días promedio para aprobar leyes (primeras dos Legislaturas)

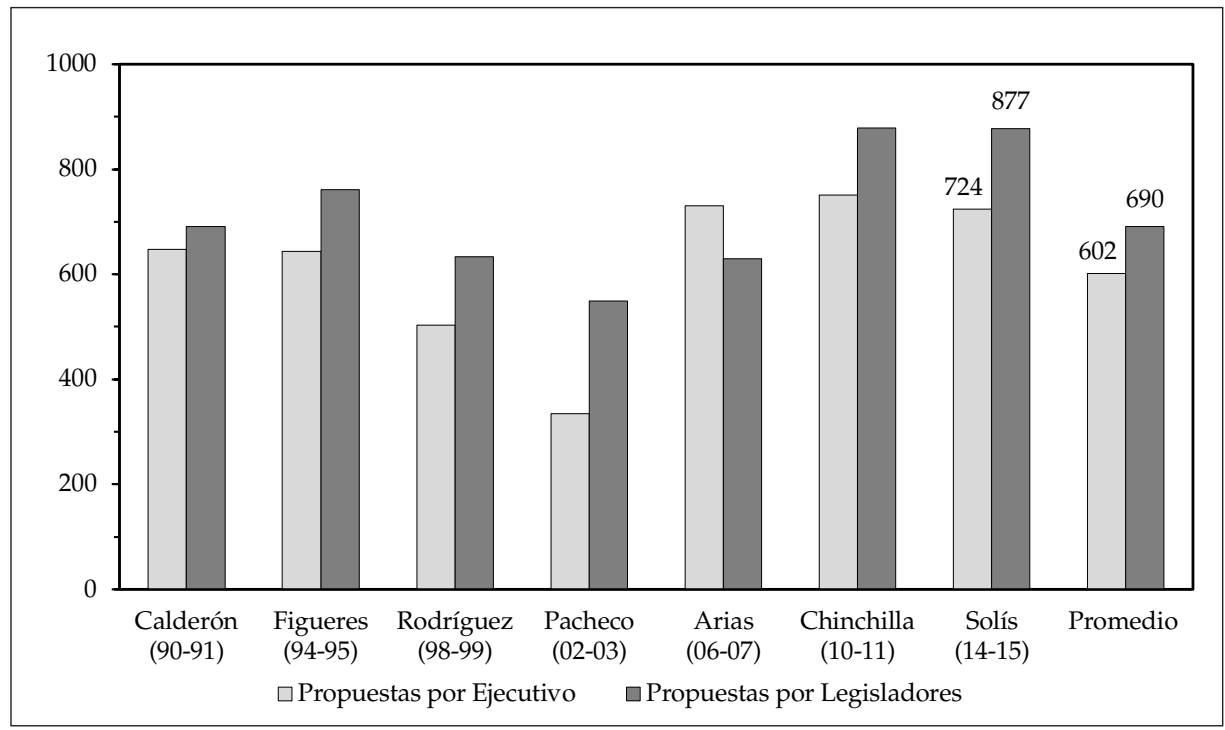

Fuente: Estado de la Nación

Este inmovilismo es explicado por la ausencia de una mayoría legislativa oficialista, la fragmentación y polarización, y las reglas internas de la Asamblea. La actual Asamblea es la más fragmentada desde la fundación de la segunda república en 1949 y la primera desde 1966 en que el partido oficialista no posee la fracción legislativa más grande. Está dividida en seis fracciones que cubren la totalidad del espectro ideológico. Situado en el centro y poseyendo el mayor número de diputados (18 de 57, 32\%), PLN es esencial para la aprobación de cualquier ley. A su izquierda está el partido oficialista, PAC, con 13 (23\%). Con nueve $(16 \%)$, FA ocupa la izquierda extrema. A la derecha del PLN está PUSC, el otro partido tradicional, con 8 (14\%). Movimiento Libertario ocupa la derecha extrema con tres (5\%) escaños. ${ }^{5}$ Además, hay cinco diputados $(9 \%)$ representantes de cuatro partidos evangélicos. Este difícil panorama es amplificado por las reglas que rigen el debate y la enmienda de proyectos de ley en la Asamblea. El actual reglamento le otorga a las minorías tremendo poder para "torpedear" proyectos a los que se oponen (Arias Ramírez 2008: 21; Borges 2014). Volviendo al ejemplo de la reforma fiscal, aprovechando de la permisividad del reglamento, diputados del Movimiento Libertario y PUSC emitieron cientos de enmiendas con el fin de atascar al proyecto en comisión y evitar que llegara a ser votado. 


\section{RELACIÓN ENTRE LOS PODERES DEL ESTADO}

Durante todo 2016, las relaciones entre el Poder Ejecutivo y el Legislativo se centraron en la discusión de un paquete de nueve proyectos de ley propuestos en agosto 2015 por la administración Solís con el fin de incrementar la recaudación de impuestos, reducir la evasión fiscal y controlar el gasto público. Si bien los seis proyectos menos controversiales fueron aprobados a finales de 2016, fracasaron los proyectos de más peso, aquellos que buscaban incrementar la recaudación de impuestos en un 2\% del PIB. En enero 2017, Solís retiró dichas reformas, convirtiéndose en el tercero de los últimos cuatro presidentes en dedicar gran parte de su mandato y gastar su limitado capital político en una reforma fiscal fracasada. La persona que asumirá la presidencia en mayo 2018 heredará preocupantes déficits fiscales y una deuda pública que se acerca a niveles insostenibles (FMI 2016).

Más allá de su efecto sobre la economía, el fracaso de la reforma fiscal es emblemático de una crisis de gobernabilidad más generalizada. Con cada administración se vuelve más difícil forjar acuerdos sobre temas nacionales de transcendencia. Desde 1994, ningún presidente ha contado con una mayoría legislativa. Los obstáculos al consenso se incrementaron aún más a partir de 2002 con la transición de un sistema bipartidista a uno multipartidista cada vez más polarizado. Los efectos de esta configuración son intensificados por el reglamento de la Asamblea, el cual le permite a grupos pequeños de diputados extender por meses e inclusive años la discusión de proyectos de ley a los que se oponen (Arias Ramírez 2008).

Dado este contexto, en 2005 se creó un mecanismo de "vía rápida" capaz de acelerar el debate de proyectos que cuentan con el apoyo de una súper-mayoría de dos tercios (38) de los diputados. Si bien esto fue un avance, la vía rápida no puede superar el obstruccionismo en contra de proyectos apoyados por una mayoría menor a los dos tercios. De tal manera, la aprobación de proyectos controversiales, hoy día, requiere de facto el apoyo de una súper-mayoría y no una mayoría simple, como dice la constitución (Borges 2014). Más aun, este procedimiento es engorroso $\mathrm{y}$, si es implementado incorrectamente, puede causar que un proyecto sea declarado inconstitucional, tal y como ocurrió con las reformas fiscales promovidas por las administraciones Pacheco y Chinchilla.

\section{Contexto}

Costa Rica se distingue a nivel latinoamericano por su paradójica combinación de un Estado de bienestar universalista y su bajo nivel de recaudación de impuestos. En otras palabras, existe "una inconsistencia entre la decisión que tomó el país hace casi medio siglo, de avanzar hacia un modelo de un Estado social de derecho, y la disposición para proveer los recursos que demanda el logro de este objetivo" (PEN 2011: 128). Múltiples estudios han demostrado 
que el nivel de recaudación de impuestos (13,3-14,1\% del PIB durante 20022014) es significativamente menor al de otros países con niveles de desarrollo comparables. Según PEN (2011), el nivel de impuestos per cápita (\$1.529) en 2007 fue \$339 menor que en países con PIB similar. Países con niveles de desarrollo humano similares, en promedio, recolectaron $\$ 2.310$ per cápita, es decir \$ 781 más por persona que Costa Rica. No se ha llevado a cabo una reforma fiscal estructural desde 1995 (Robles Cordero 2015).

Desde el inicio del siglo, expertos, tanto locales como internacionales, han recomendado que el gobierno implemente una reforma comprensiva. Específicamente, se ha recomendado que el país ponga mayor énfasis en la recolección del impuesto sobre le renta y transforme el actual impuesto de ventas, el cual únicamente cubre bienes, en un impuesto al valor agregado (IVA) que cubra tanto bienes como servicios. Estas fueron las metas de las reformas intentadas por las administraciones Pacheco y Chinchilla. Ambos gobiernos invirtieron gran cantidad de capital político promoviendo reformas que pasaron años en la Asamblea donde enfrentaron "carretillos llenos de mociones" propuestos por Movimiento Libertario y otros partidos de oposición.

Si bien las debilidades fiscales del gobierno no son nuevas, este tema adquirió urgencia luego de la crisis financiera global de 2008-2009. Como respuesta a la crisis, la administración Arias implementó un estímulo contracíclico que incluyó alzas salariales y nuevas plazas en el sector público, aumentos en las pensiones no contributivas y la expansión de transferencias monetarias condicionadas (Feoli 2009; Villareal y Gómez 2010), gastos que se tornaron permanentes. La economía no recuperó el nivel de crecimiento que tuvo previo a la crisis. Naturalmente, la combinación de mayor gasto y menor crecimiento resultó en mayores déficits $y$, por ende, creciente endeudamiento.

\section{El proceso político}

Aumentar impuestos siempre es políticamente difícil. Robles Cordero (2015) analiza todos los intentos de reforma fiscal en Costa Rica desde 1982. Sus hallazgos predecían un escenario oscuro para las propuestas de Solís. Las reformas tienen mejores posibilidades de éxito cuando son simples (con pocos artículos) y el partido del Presidente posee una mayoría legislativa y controla las presidencias de la Asamblea y de la comisión dictaminadora. Además, la ventana para aprobar estos proyectos es corta. Entre más tiempo pasa un proyecto en la Asamblea, más difícil se vuelve su aprobación.

Solís cometió un grave error al no proponer las reformas durante su "luna de miel". Comenzó a circular sus propuestas en marzo de 2015 pero no las envió a la Asamblea hasta agosto, dándoles tiempo a sus oponentes para organizarse. Para ese entonces, PAC había perdido control de la presidencia de la Asamblea y con ello la presidencia de la Comisión de Asuntos Hacendarios. Dicha comisión quedó en manos de Rosibel Ramos (PUSC), quien se opuso consistentemente a 
los nuevos impuestos. Es debatible si la decisión de dividir la reforma en nueve proyectos fue acertada. Por un lado, reemplazó una reforma compleja con varias más simples. Por el otro, perdió la habilidad de ofrecerle a la derecha controles sobre el gasto a cambio de nuevos impuestos. De tal manera, se aprobaron las reformas al gasto, específicamente las leyes sobre contrabando, fraude fiscal, pensiones públicas, caja única y exoneraciones fiscales. Sin embargo, las dos grandes reformas - renta e IVA — nunca salieron de comisión. La administración tuvo más éxito con el restablecimiento del impuesto sobre sociedades, el cual se utilizará para fortalecer a la policía.

Pero más allá de estos errores tácticos, el juego político alrededor de las reformas era particularmente difícil, sino imposible. Juntos PAC y PLN, los dos partidos que más han apoyado las reformas fiscales, representaban una mayoría simple de la Asamblea (31 diputados, 54\% de los escaños). Sin embargo, dado el deseo del Movimiento Libertario y, en menor grado, PUSC de descarrilar el proceso, la reforma fiscal requería una súper-mayoría. De tal manera, los 13 (23\%) del PAC requerían apoyo tanto de los 18 (32\%) del PLN a su derecha como de los nueve $(16 \%)$ del FA a su izquierda. ${ }^{6}$ PLN condicionaba su apoyo a la aprobación de un proyecto para limitar los beneficios extra-salariales de los empleados públicos. Pero apoyar a dichas reformas le costaría al PAC el apoyo del FA, que es apoyado por sindicatos de empleados públicos. El apoyo del PLN dependía en alienar al FA y viceversa.

La opinión pública y los principales grupos de interés tampoco favorecían al acuerdo. Si bien, a finales de 2016, un $82,5 \%$ consideraba al déficit fiscal "muy importante", solo 11,4\% apoyaba reducirlo a través de un alza de impuestos (CIEP 2016). La mitad de los encuestados (50,5\%) opinaba que el déficit debería reducirse exclusivamente a través de recortes al gasto. Sin embargo, los encuestados se mostraron poco proclives a apoyar recortes. Las únicas excepciones fueron en los gastos en elecciones y embajadas, ambos insignificantes en comparación con los salarios y pensiones que dominan el presupuesto. Tanto la cúpula empresarial como los principales sindicatos del sector público se oponían a la creación de nuevos impuestos y al alza de impuestos existentes. Los empresarios demandaban controles sobre salarios y pensiones. Los sindicatos se oponían a la creación del IVA y reformas a los beneficios de los empleados públicos (CRHoy.com 2016, 4 de enero).

\section{Comparación con proyectos pasados}

Los problemas enfrentados por esta reforma fiscal fueron cualitativamente diferentes de los enfrentados por las dos reformas que le precedieron. Luego de años de discusión, las dos reformas previas lograron obtener el apoyo de súper-

Una alianza entre PAC, los diputados cristianos y PLN (36 o 63\%) o FA (27 o 47\%) habría sido insuficiente para activar la vía rápida. 
mayorías legislativas. Fueron votadas y aprobadas antes de ser declaradas inconstitucionales debido a vicios procedimentales en el uso de la vía rápida. De tal modo, queda claro que esta constituye una estrategia riesgosa. Sin embargo, dada la intransigencia de los Libertarios y, en menor grado, de PUSC, dicha herramienta constituye la única manera de sanear las finanzas públicas. Estas reformas llegaron a ser votadas porque las Asambleas que enfrentaban eran menos fragmentadas y polarizadas que la actual (ver cuadro 1). Dichas asambleas contaban con un partido de centro-izquierda (PAC), uno de centro (PLN), uno de centro-derecha (PUSC) y uno de derecha (Libertario) además de unos cuantos diputados de partidos minoritarios. Al introducir un partido de izquierda, la elevación del FA en 2014 dificultó la construcción de consensos.

Cuadro 1. Características principales de la Asamblea Legislativa (1990-2014)

\begin{tabular}{lccccccc}
\hline & 1990 & 1994 & 1998 & 2002 & 2006 & 2010 & 2014 \\
\hline Número efectivo de Partidos $^{\mathrm{a}}$ & 2.21 & 2.30 & 2.56 & 3.68 & 3.32 & 3.90 & 4.92 \\
Polarización $^{\mathrm{b}}$ & -- & 2.92 & 3.54 & 2.79 & 4.24 & 4.07 & 4.33 \\
\hline
\end{tabular}

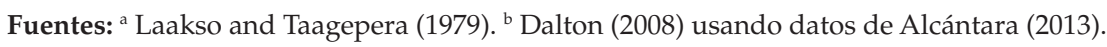

PAC ha apoyado las tres reformas. PUSC ha apoyado reformas únicamente durante la administración Pacheco, cuando controlaba al gobierno. PLN apoyó a las primeras dos reformas y se mostró dispuesto a apoyar la tercera, pero únicamente si se implementaban las reformas a los beneficios extra-salariales de los empleados públicos. Pero dichos beneficios eran anatema para FA. De tal manera, usando el lenguaje de jugadores de veto (Tsebelis 2005), simplemente no existía un winset bajo el cual el statu quo podía ser reformado. Este resultado es poco alentador e introduce serias dudas sobre la capacidad de futuros gobiernos de solucionar la crisis fiscal actual y, más generalmente, armar consensos sobre otros temas nacionales de transcendencia.

\section{VII.EVALUACIÓN SOBRE EL FUNCIONAMIENTO Y CALIDAD DE LA DEMOCRACIA}

Costa Rica es una democracia consolidada en rumbo hacia elecciones presidenciales y legislativas y su decimoséptima transferencia de poder pacífica consecutiva. Pero detrás de este éxito existe una seria crisis de gobernabilidad. La parálisis que afecta al gobierno es producto de la mezcla volátil de presidencialismo y un sistema multipartidista cada vez más fragmentado y polarizado. Estas dificultades son amplificadas por la debilidad de la presidencia (Carey 1996) y por un reglamento legislativo que le otorga a las minorías poder de veto (Arias Ramírez 2008; Borges 2014). Obtener una mayoría simple en un congreso con seis fracciones ideológicamente distantes es un reto. Más difícil 
aun es forjar las súper-mayorías necesarias para sobreponerse al filibusterismo y activar el mecanismo de "vía rápida".

El fracaso de las reformas fiscales propuestas por las administraciones Pacheco, Chinchilla y Solís es emblemático de la inhabilidad de la clase política costarricense de resolver temas nacionales de transcendencia. Si bien las encuestas de opinión pública no muestran a la reforma fiscal como una prioridad entre los costarricenses (CIEP 2016), esta es esencial para atender las demás demandas del electorado. La perpetuidad de las discusiones alrededor de este tema desgasta los gobiernos y erosiona la legitimidad del sistema político por tres razones:

Primero, las alzas de impuestos son, por definición, impopulares. El pasar meses y años discutiendo reformas que, si bien cruciales, son impopulares congela la imagen del "paquetazo de impuestos" en la mente del electorado. Para peor, como la reforma nunca llega a aprobarse, el electorado tampoco recibe los potenciales beneficios de esta política dolorosa e impopular. Dicho de otra manera, los gobiernos pagan el precio por querer alzar los impuestos sin después obtener los réditos provenientes de las políticas financiadas por los nuevos impuestos. Ya que la política fiscal es impopular, los gobiernos desearían implementarla rápidamente "como arrancar una curita". Lo opuesto ocurre. Los oponentes usan "carretillos llenos de mociones" para atropellar a las mayorías y hacer al proceso lo más largo y doloroso posible.

Segundo, las largas discusiones sobre las reformas fiscales tienen el efecto de "succionar todo el aire de la habitación". El tiempo que el ejecutivo y los diputados dedican a negociar e implementar procedimientos legislativos arcanos para sobreponerse al filibusterismo es tiempo que no dedican a resolver otras demandas del electorado. El votante queda con la impresión de que alzar los impuestos es una de las pocas prioridades de la clase gobernante: un fin, no un medio.

Tercero, la inhabilidad del Ejecutivo y de los diputados de resolver el tema año tras año, administración tras administración, refuerza la imagen de que el gobierno "no hace nada". Meses de titulares en los medios de comunicación detallando la dificultad (¿o futilidad?) de construir consensos interpartidarios confirma las peores sospechas del electorado sobre los políticos y los partidos.

A pesar de ser la democracia más longeva en Latinoamérica y poseer los niveles de apoyo al sistema más altos de la región, la democracia costarricense ha experimentado una importante caída en niveles de aprobación desde los ochenta (Seligson 2002). Este descontento es tanto la causa como la consecuencia de la transición al multipartidismo. Seligson y Martínez Franzoni $(2010,331)$ acertadamente atribuyen parte de este descontento a la decreciente efectividad de la Asamblea. Si bien expandió las alternativas disponibles a los votantes, el multipartidismo produjo una Asamblea fragmentada, polarizada y poblada por 
diputados con poca experiencia. Estas tendencias, en combinación con el actual reglamento, han paralizada a la Asamblea y, por ende, al sistema político entero.

El bienestar de la democracia costarricense depende de la habilidad de los principales actores políticos de forjar acuerdos que destraben la Asamblea. Sin embargo, estos tipos de acuerdos son poco probables bajo el actual reglamento. Es urgente construir una súper-mayoría capaz de reformar el reglamento. Pero esto requeriría que los diputados valoren al bienestar del país por encima de su habilidad de vetar legislación futura. La genialidad de la democracia es que los perdedores de las grandes batallas políticas viven para luchar otro día y convencer al electorado de que su visión es la correcta. La democracia costarricense requiere mejores perdedores.

\section{REFERENCIAS}

Agência Brasil. 2016, 12 de junio. "Redução de trabalho motiva saída de imigrantes e refugiados do Brasil." Recuperado de http://agenciabrasil.ebc.com.br/direitos-humanos/ noticia/2016-12/reducao-de-trabalho-motiva-saida-de-imigrantes-e-refugiados-do

Alcántara, Manuel (ed). 2013. Proyecto de elites parlamentarias latinoamericanas (PELA). Universidad de Salamanca. Recuperado de http:/ / americo.usal.es/oir/elites

Alfaro-Redondo, Ronald y Steffan Gómez-Campos. 2014. "Costa Rica: Elecciones en el contexto político más adverso arrojan la mayor fragmentación partidaria en 60 años." Revista de Ciencia Política 34(1): 125-44.

Alfaro-Redondo, Ronald. 2015. "Análisis electoral y de partidos políticos en Costa Rica." Ponencia preparada para el Informe Estado de la Nación. San José: PEN.

Alfaro-Redondo, Ronald. 2016. "Costa Rica: Fuerte interdependencia entre actores genera un contexto de parálisis y enfrentamiento político." Revista de Ciencia Política 36(1): 103-21.

Arias Ramírez, Bernal. 2008. "Estudio comparativo de normativa parlamentaria (Costa Rica confrontada con selección de países de Europa y América Latina) ¿Es perjudicial el Reglamento Legislativo costarricense"? Ponencia preparada para el Informe Estado de la Nación. San José: PEN.

BCCR [Banco Central de Costa Rica]. 2017. Programa macroeconómico 2017-2018. San José: BCCR.

Borges, Fabián A. 2014. "Rules of Procedure as a Cause of Legislative Paralysis: The Case of Costa Rica, 2002-2012." Latin American Politics and Society 56(4): 119-142.

Carey, John M. 1996. Term Limits and Legislative Representation. Nueva York: Cambridge University Press.

Cascante Segura, Carlos Humberto, Raúl Fonseca Hernández, Marco Vinicio Méndez Coto y María Fernanda Morales Camacho. 2016. "Seguimiento a la política exterior de Costa Rica (2014-2016)". Ponencia preparada para el Informe Estado de la Nación. San José: PEN.

CEPAL [Comisión Económica para América Latina]. 2016. Panorama social de América Latina 2015. Santiago: CEPAL.

CIEP [Centro de Investigaciones y Estudios Políticos]. 2016. $4^{\circ}$ informe de percepciones sobre reforma fiscal en Costa Rica. San José: CIEP-UCR.

CIEP. 2017. Informe de encuesta sociopolítica de noviembre 2016. San José: CIEP-UCR.

El Comercio. 2015, 6 de noviembre. "Ecuador, la primera parada de los cubanos que llegan a México buscando 'salvoconducto' para EE.UU." Recuperado de http://www.elcomercio.com/actualidad/ecuador-primera-parada-cubanos-estadosunidos.html

CRHoy.com. 2016, 4 de enero "Reforma fiscal domina expectativas de sectores para 2016." Recuperado de http://www.crhoy.com/archivo/reforma-fiscal-domina-expectativas-de-sectores-para-2016/nacionales/ 
Dalton, Russell J. 2008. "The Quantity and the Quality of Party Systems: Party System Polarization, Its Measurement, and Its Consequences." Comparative Political Studies 41(4): 899-920.

Diario Extra. 2017, 4 de mayo. "Juan Diego Castro se dispara en encuestas." Recuperado de http:/ / www.diarioextra.com/Noticia/detalle/331603/juan-diego-castro-se-dispara-en-encuestas

INEC [Instituto Nacional de Estadística y Censos]. 2016. Encuesta nacional de hogares julio 2016: resultados generales. San José: INEC.

INEC. 2017. Encuesta continua de empleo: indicadores del mercado laboral costarricense, cuarto trimestre. 2017. San José: INEC.

El Financiero. 2014, 30 de abril. "Es falso que la Costa Rica de hoy es más desigual que la de hace 10 años." Recuperado de http:/ / www.elfinancierocr.com/economia-y-politica/ falso-Costa-Rica-desigual-hace_0_509949008.html

El Financiero. 2015, 8 de noviembre. "Pobres de Costa Rica son cada vez más pobres". Recuperado de http:/ / www.elfinancierocr.com/economia-y-politica/pobreza-IPM-ingresos-Enaho-Encuesta_Nacional_de_Hogares-INEC_0_842915732.html

El Mundo CR. 2016, 9 de diciembre. "Ticos dan buena nota al Gobierno y Municipalidades ante emergencia por Huracán Otto." Recuperado de http://www.elmundo.cr/ ticos-dan-buena-nota-al-gobierno-y-municipalidades-ante-emergencia-por-huracan-otto/

El Mundo CR. 2017, 15 de febrero. “Epsy Campbell y Oscar Arias los personajes políticos con mayor índice de opinión positiva." Recuperado de http://www.elmundo.cr/ epsy-campbell-oscar-arias-los-personajes-politicos-mejor-opinion/

Feoli, Ludovico. 2009. "Costa Rica después del TLC: ¿la calma que sigue a la tempestad?" Revista de Ciencia Política 29, (2): 355-79.

FMI [Fondo Monetario International]. 2016. "2016 Article IV Consultation-Press Release; Staff Report' And Statement by the executive director for Costa Rica." Washington: FMI.

Gómez-Campos, Steffan y Evelyn Villarreal. 2013. “Costa Rica: la derrota prematura de un gobierno dividido Costa Rica". Revista de Ciencia Política 33(1): 117-34.

Guillén Araya, María José. 2016. "El Panorama de las Acciones Colectivas en Costa Rica". Ponencia preparada para el Informe Estado de la Nación. San José: PEN.

Krogstad, Jens Manuel. 2017, 13 de enero. "Surge in Cuban immigration to U.S. continued through 2016". Pew Research Center. Recuperado de http://www.pewresearch.org/ fact-tank/2017/01/13/cuban-immigration-to-u-s-surges-as-relations-warm/

Laakso, Markku, and Rein Taagepera. 1979. "Effective Number of Parties: A Measure with Application to West Europe." Comparative Political Studies 12(1): 3-27.

Loría, Max. 2015. "Evolución de la seguridad ciudadana en el 2014." Ponencia preparada para el Informe Estado de la Nación. San José: PEN.

La Nación. 2015, 30 de abril. "PUSC y Frente Amplio se alejan de la candidatura de Ottón Solís." Recuperado de http://www.nacion.com/nacional/politica/PUSC-aleja-candidatura-Otton-Solis_0_1484651627.html

La Nación. 2015, 10 de noviembre. "Policía desarticula banda internacional de tráfico de personas." Recuperado de http://www.nacion.com/sucesos/crimenes-asaltos/Fiscalia-desarticula-internacional-trafico-personas_0_1523447712.html

La Nación. 2016, 15 de marzo. “Cubanos que no tenían dinero salieron este martes de Costa Rica." Recuperado de http://www.nacion.com/nacional/politica/migrantes_cubanos-Costa_Rica-Mexico-El_Salvador_0_1548645197.html

La Nación. 2016, 26 de abril. "Compra de 50 tanques rusos en Nicaragua preocupa a Costa Rica." Recuperado de http://www.nacion.com/nacional/politica/Compra-Nicaragua-preocupa-Costa-Rica_0_1557044382.html

La Nación. 2016, 28 de septiembre. “Costa Rica espera que deportaciones en EE.UU. reduzcan migración de haitianos." Recuperado dehttp:/ / www.nacion.com/nacional/politica / Costa-Rica-deportaciones-EE-UU_0_1588041198.html 
La Nación. 2016, 22 de octubre. "Luis Guillermo Solís: Chinchilla 'nos heredó una alta percepción de corrupción política."' Recuperado de http:/ /www.nacion.com/nacional/ politica/Luis-Guillermo-Solis-escandalos-privado_0_1592840763.html

La Nación. 2016, 16 de noviembre. “Otto Guevara: La campaña de Donald Trump 'nos da más bríos."' Recuperado de http://www.nacion.com/nacional/politica/Otto-Guevara-Campana-Donald-Trump_0_1597440330.html

La Nación. 2016, 2 de diciembre. "Personajes 2016: Otto, el huracán que azotó Costa Rica." Recuperado de http://www.nacion.com/sucesos/desastres/Personajes-Otto-huracan-Costa-Rica_0_1601439870.html

La Nación. 2017, 3 de enero. "Crímenes aumentaron en Costa Rica en último año."Recuperado de http://www.nacion.com/sucesos/crimenes-asaltos/Crimenes-aumentaron-pais-ultimo-ano_0_1607439260.html

La Nación. 2017, 21 de enero. "Precandidato del PAC plantea continuismo de Gobierno de Luis Guillermo Solís." Recuperado de http://www.nacion.com/nacional/politica/ Exministro-trabajo-precandidatura-asamblea-PAC_0_1611038927.html

La Nación. 2017, 20 de febrero. “Deuda del Gobierno llegará al 61,20\% del PIB en el 2020 sin la reforma fiscal." Recuperado de http://www.nacion.com/economia/Deuda-Gobierno-llegara-PIB-reforma_0_1617038344.html

La Nación. 2017, 1 de marzo. “ $\not 130.000$ millones cuesta recuperar las zonas afectadas por huracán Otto." Recuperado de http://www.nacion.com/sucesos/CNE-millones-recuperacion-huracan-Otto_0_1618838132.html

La Nación. 2017, 3 de abril. "Álvarez Desanti retira la palabra fraude` pero critica el trabajo del Tribunal Electoral del PLN." Recuperado de http://www.nacion.com/nacional/ politica/Alvarez-Desanti-critica-TEI-PLN_0_1625437499.html

PEN [Programa Estado de la Nación]. 2011. Decimoctavo Informe Estado de la Nación en Desarrollo Humano Sostenible. San José: PEN.

Robles Cordero, Edgar. 2015. “Intentos de Reforma Fiscal en Costa Rica (1982-2015).” Recuperado de https:/ / ciep.ucr.ac.cr/images/REFORMAFISCAL/Intentos\%20de\%20Reforma\%20Fiscal\%20en\%20Costa\%20Rica.pdf

Rosales Valladares, Rotsay. 2015. “Elecciones Costa Rica 2014: El Aparente Giro Hacia el Progresismo de Izquierda Mediante el Triunfo del Partido Acción Ciudadana y el Ascenso del Frente Amplio". Anuario Centro de Investigación y Estudios Políticos 6: 155-175.

Ross, Wilbur y Peter Navarro. 2016, 15 de Agosto. "Why Trump has a better economic plan than Clinton." CNBC. Recuperado de http://www.cnbc.com/2016/08/15/whytrump-has-a-better-economic-plan-than-clinton-wilbur-ross-commentary.html

Seligson, Mitchell A. 2002. "Trouble in Paradise: The Impact of the Erosion of System Support in Costa Rica, 1978-1999". Latin American Research Review 37(1): 160-85.

Seligson, Mitchell A. y Juliana Martínez Frazoni. 2010. “Limits to Costa Rican Heterodoxy: What Has Changed in 'Paradise'"? En The Politics of Democratic Governance in Latin America, editado por Scott Mainwaring y Timothy Scully. Stanford: Stanford University Press, 307-37.

Tsebelis, George. 2002. Veto Players: How Political Institutions Work. Princeton: Princeton University Press.

Vargas Cullell, Jorge, Luis Rosero-Bixby y Mitchell A. Seligson. 2006. The Political Culture of Democracy in Costa Rica: 2006. San José: LAPOP/CCP-UCR.

Villarreal F., Evelyn y Steffan Gómez A. 2010. “Costa Rica 2009: Enfrentando la crisis internacional en plena campaña electoral”. Revista de Ciencia Política 30(2): 275-96.

Fabián Borges es profesor asistente de Ciencias Políticas en la Universidad Estatal de California, San Bernardino. Es doctor en Ciencias Políticas de la Universidad del Sur de California y Master en Estudios Latinoamericanos de la Universidad de Georgetown. E-mail: fabian.borges@csusb.edu. 